
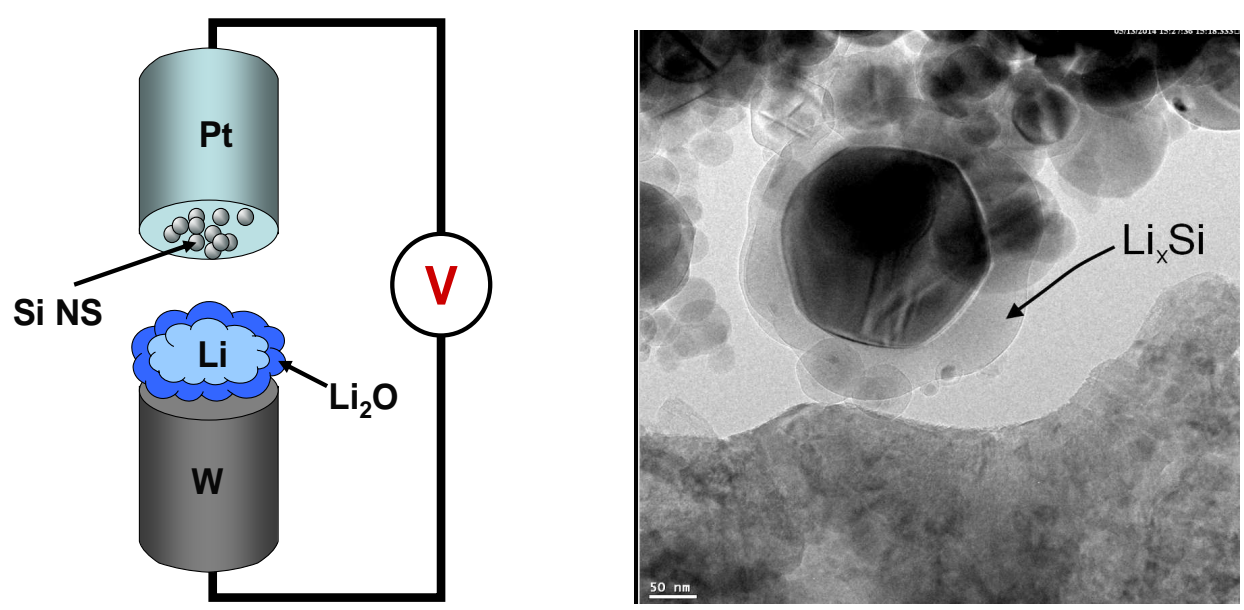


\title{
In situ transmission electron microscopy observations of lithiation of silicon nanopowder produced by induced plasma atomization
}

\author{
LEBLANC, Dominic $^{\text {ad }}$, WANG, Chongmin ${ }^{\mathrm{b}}, \mathrm{HE}$, Yang $^{\mathrm{c}}$, BÉLANGER, Daniel $^{\mathrm{d}}$ and ZAGHIB, \\ $\operatorname{Karim}^{\mathrm{a} *}$
}

${ }^{\mathrm{a}}$ Hydro-Quebec Research Center (IREQ), 1800 boul. Lionel-Boulet, Varennes (Qc), J3X 1S1, Canada

${ }^{\mathrm{b}}$ Environmental Molecular Sciences Laboratory (EMSL), Pacific Northwest National Laboratory (PNNL), 902 Battelle Boulevard, P.O. Box 999, MSIN K8-93, Richland, WA 99352, USA

${ }^{\mathrm{c}}$ Department of Mechanical Engineering and Materials Science, University of Pittsburgh, 3700 O’Hara Street, Pittsburgh, PA 15261, USA

'Université du Québec à Montréal (UQÀM), Case postale 8888, succursale Centre-ville, Montréal (Qc), H3C 3P8, Canada

\section{- Corresponding author *}

ZAGHIB, Karim Hydro-Québec Research Center 1800, boul. Lionel-Boulet Varennes (Qc) J3X 1S1

Canada

Tel.: +1 4506528019

Fax: +14506528424

zaghib.karim@ireq.ca 


\begin{abstract}
Composite Li-ion anode can be fabricated using silicon nanopowders synthesized by induced plasma atomization. Properties of such nanopowder were characterized by physical and electrochemical methods. Primary particles were crystalline with spherical shape and the typical diameter ranging from 50 to $200 \mathrm{~nm}$. The Si nanopowder showed a high gravimetric capacity (4900 mAh/g) at first discharge and around 12\% irreversible loss of lithium. In addition, observations of a single silicon particle made by in situ TEM permitted to compare the volume change during lithiation with other silicon anode nanomaterials.
\end{abstract}

\title{
Keywords
}

Silicon nanopowder, Anode, Li-ion battery, In situ TEM, Plasma atomisation 


\section{Introduction}

Carbonaceous materials are typically used in the negative electrode for Li-ion batteries. Because higher energy Li-ion batteries are demanded in electric vehicles, alternative electrode materials are being sought. Silicon is an attractive alternative material due to its high theoretical gravimetric capacity density of $4200 \mathrm{mAh} / \mathrm{g}$ when the $\mathrm{Li}_{4.4} \mathrm{Si}$ phase is formed $[1,2]$. In spite of this advantage, Si-based anodes show numerous problems that prevent their use in commercial Li-ion batteries. A significant capacity fade occurs during cycling and low coulombic efficiency is obtained. The performance degrades during the first few cycles due to the large volume change during charge/discharge. It ultimately leads to mechanical degradation and loss of electrical contacts $[1,3,4]$. However, when small particles [5, 6] or thin-films [7, 8] containing silicon are used as the negative electrode, performance and cycle life improves markedly. It is recognized that nanoscale materials can be reversibly deformed far beyond the limit of large-grained materials; this phenomenon is called superplasticity [9]. Moreover, recent in situ methods based on transmission electron microscopy have provided new insights into the expansion/contraction during lithium insertion/extraction in silicon nanoparticles and nanowires [10-12].

Large-scale application of silicon as anode in Li-ion batteries will require suitable synthetic methods. An attractive method for the fabrication of silicon nanopowders, from micrometric silicon particles, is based on induced plasma atomization because of the high temperature processing capability and high quenching rates that can be achieved [13]. Nanoparticles produced by plasma have high crystalline structure, spherical morphology, narrow particle size distribution and high purity [14].

This study reports the synthesis of silicon nanopowders by induced plasma method and both their physical and electrochemical characterization. In addition, the volume change during lithiation of 
a single silicon particle in the presence of smaller particles is investigated by in situ transmission electron microscopy (TEM) to be compared with other silicon anode nanomaterials.

\section{Experimental}

\subsection{Powder synthesis}

Spherical silicon nanopowder (Si NS) was synthesized by induced plasma atomization using a $3 \mathrm{MHz}, 60 \mathrm{~kW}$ RF plasma torch (Tekna Plasma Systems). The powder was prepared from a micrometric $99.999 \mathrm{wt} \%$ pure $(5 \mathrm{~N})$ silicon powder in a pure evaporation-condensation manner. More specifically, the micrometric silicon powder was heated and evaporated in the plasma torch. The resultant vapors were subsequently quenched very rapidly and homogeneous nucleation led to the formation of a fine nanopowder aerosol (Fig. 1).

To prevent any surface contamination (or passivation), handling of the nanosilicon powder and its packaging in metal-plastic bags were done in an argon-filled glove box.

\subsection{Powder characterization}

The silicon nanopowder morphology was observed using a Hitachi S-4700 scanning electron microscope with a field emission electron gun (FE-SEM) and a FEI Titan 80-300 scanning/transmission electron microscope (S/TEM), which is fitted with a probe forming lens aberration corrector and operated at $300 \mathrm{kV}$. Phase composition and structure were analyzed by using a Rigaku MiniFlex 600 X-ray diffractometer (XRD) with a cobalt source. The particle size was measured by laser scattering method with a Horiba LA-950V2 and by BET gas adsorption method with a Quantachrome Quadrasorb SI. 


\subsection{Electrode preparation and coin cell assembly}

The silicon nanopowder was mixed with acetylene carbon black (Denka Black) and sodium alginate (Aldrich) with a ratio of 50:25:25 using water as solvent to a viscosity of $\sim 8500 \mathrm{cP}$ for coating. A high-energy mixer (SPEX Certiprep) was used to de-agglomerate and mix the nanopowder. The slurry was coated on a copper foil to achieve loadings of approximately $0.6 \mathrm{mg} / \mathrm{cm}^{2}$. The electrode was pre-dried at $75^{\circ} \mathrm{C}$ in a convection oven and then carefully dried at $110^{\circ} \mathrm{C}$ under mild vacuum for $12 \mathrm{~h}$.

CR2032 coin cells (Hohsen) were assembled in a He-filled glove box using a Celgard 3501 separator and $200 \mu \mathrm{m}$ lithium foil anode (FMC Lithium). The electrolyte was composed of $1 \mathrm{M}$ $\mathrm{LiPF}_{6}$ in a mixture of ethylene carbonate (EC) and diethyl carbonate (DEC) (7:3 by volume) with the addition of $2 \mathrm{v} \%$ of vinylene carbonate (VC) (Ube). The cells were galvanostatically charged and discharged at $25^{\circ} \mathrm{C}$ using a VMP3 cycler (Bio-Logic) with a C/24 rate for formation cycles and a $\mathrm{C} / 6$ rate for life cycles over the voltage range of $0.005-1.0 \mathrm{~V}$ vs. $\mathrm{Li} / \mathrm{Li}^{+}$.

\subsection{In situ TEM observation of lithiation of the nanoparticle}

The structural evolution of the nanoparticle upon lithiation was observed by in situ TEM in an open-cell configuration as illustrated in Fig. 2 [12]. The silicon nanoparticles were loaded on a platinum electrode, which was fixed on one side of a Nanofactory holder. Lithium metal was used as the lithium source, which was loaded on a tungsten tip. Surface lithium oxide served as the solid electrolyte. The tungsten tip was fixed to a piezosystem on the other side of the Nanofactory holder. Titan 80-300 with a probe corrector and operated at $300 \mathrm{kV}$ was used for imaging. The insertion of lithium (or extraction) in the particle was controlled by the applied bias voltage using a potentiostat. 


\section{Results and discussion}

\subsection{Powder morphology characterization}

Fig. 3a shows a SEM micrograph of the morphology and typical size of silicon nanoparticles with primary spherical particles and their typical diameter ranging from 50 to $200 \mathrm{~nm}$. The average particle size $\left(d_{50}\right)$, determined by measuring specific surface (BET), is $85 \mathrm{~nm}\left(30 \mathrm{~m}^{2} / \mathrm{g}\right)$. Fig. $3 b$ is a TEM micrograph of the crystalline lattice in the silicon (c-Si) nanoparticles with a contamination-free atomic surface. Fig. 3c presents the XRD diffractogram of the nanopowder, with clear identification of $\mathrm{c}-\mathrm{Si}$ with the diamond cubic lattice $(\mathrm{a}=5.43 \AA$ ) and no significant amount of impurity phase. Fig. 3d shows the particle size distribution and confirms that the c-Si primary particles produced by plasma process have a typical particle size between 50 and $200 \mathrm{~nm}$ with a few larger agglomerates.

\subsection{Electrochemical characterization}

Fig. 4a shows the two first cycles (formation cycles) of the coin cell with a $\mathrm{C} / 24$ rate of charge. The first discharge (insertion of lithium) has a high gravimetric capacity (4900 mAh/g), however, around $12 \%$ of lithium is irreversibly lost after the first charge. Since silicon nanopowder is a high surface area material, surface side-reactions with the electrolyte are playing an important part of initial capacity loss; this explains the "extra" lithium beyond $\mathrm{Li}_{4.4} \mathrm{Si}$ (i.e. $4200 \mathrm{mAh} / \mathrm{g}$ ).

The first discharge curve (first lithium insertion) shows a typically flat shape, which corresponds to the amorphization of the crystalline silicon. Once electrode formation is complete, the voltage during deinsertion has an average value of $0.4 \mathrm{~V}$ versus $\mathrm{Li}^{2} \mathrm{Li}^{+}$, which is $0.2 \mathrm{~V}$ higher than graphite; this has a negative impact on cell energy density when silicon is used as anode. We can 
also notice that, probably because of significant volume change during $\mathrm{Li}^{+}$insertion/deinsertion, the hysteresis loop is rather large for silicon. This phenomenon is often related to mechanical work (mechanical strain energy) during particle deformation [15].

Fig. $4 \mathrm{~b}$ shows the cycling change of the coin cell at $\mathrm{C} / 6$ rate which is used to measure the cycle life. We clearly see that the silicon electrode loses $20 \%$ of its initial capacity after approximately 20 cycles. Limiting the depth of discharge (DoD) is one possible method to improve calendar life of the silicon anode.

The silicon powder shows impressive results for silicon synthesized by induced plasma, which produced nanometric particle size, spherical shape and no surface contamination. However, the cycle life of the cell is still poor according to the best performance reported in the literature [16]. It was suggested that cycle life of lithium cells with c-Si anode materials is mainly limited by large structural volume change followed by particle pulverization and the loss of particles contact during insertion/deinsertion cycles [17]. It was also reported that strain can be accommodated without fracture below a critical particle size of $150 \mathrm{~nm}$ [18]. One of our goals is to further investigate the silicon powder using the in situ TEM as a practical tool to understand the changes at the nanoparticle level.

\subsection{In situ TEM lithiation}

Fig. 5a shows a TEM micrograph of a typical $200 \mathrm{~nm}$ pristine spherical silicon particle synthesized by induced plasma. The same particle is contacted by $\mathrm{Li}^{2} / \mathrm{Li}_{2} \mathrm{O}$ in Fig. 5 b. A bias potential of $-2 \sim-5 \mathrm{~V}$ was used to start lithiation of the silicon particle. At this point, a rapid reaction from the interior of the particle was observed, forming a core-shell structure. The crystalline core (dark gray contrast) was gradually transformed to amorphous $\mathrm{Li}_{\mathrm{x}} \mathrm{Si}$ alloy (light gray). The thickness of the amorphous phase was not uniform around the particle and resulted in 
a anisotropic lithiation [19]. Crack formation was not observed, however, we were not able to fully lithiate the larger particles $(200 \mathrm{~nm})$ in our experiment. Since the particles were clustered together and that no conductive binder was used, the conductivity might have been too low to achieve full lithiation (Video1). But, some smaller particles $(\sim 50 \mathrm{~nm}$ in Fig. $5 \mathrm{c})$ did fully react with lithium without fracturing. In a recent study, McDowell et al. also observed that the c-Si particles undergo anisotropic lithiation and volume expansion leading to a faceted Si core with the lithiated phase very nearly fully lithiated [10].

\section{Conclusion}

In this work, we characterized the morphological and electrochemical properties of $\mathrm{Si}$ nanopowder produced by the induced plasma atomization process. The primary particles were crystalline with spherical shape and typical diameter between 50 to $200 \mathrm{~nm}$. The c-Si nanopowder shows a high gravimetric capacity $(4900 \mathrm{mAh} / \mathrm{g})$ at first discharge and around $12 \%$ irreversible loss of lithium. The potential against lithium during deinsertion was $0.4 \mathrm{~V}$; this has a negative impact on cell energy density. The cycle life was also short as after 20 cycles, the cell was at $80 \%$ of the initial capacity. To improve the cycle life of this anode, it may be necessary to operate at lower depth of discharge (DoD).

In situ TEM provided better insight on the degradation mechanism of the silicon nanoparticles. The open-cell configuration permitted observations of the volume change of silicon during lithiation. We observed anisotropic lithiation of the c-Si particle. Crack formation was not observed, maybe because the large particles $(\sim 200 \mathrm{~nm})$ were not fully lithiated. However, we clearly saw that smaller c-Si particles $(10-20 \mathrm{~nm})$ did not crack.

This cell design was inherently different from a real cell, where a liquid electrolyte forms conformal contact with the electrode materials and a conductive matrix is used. The open-cell 
configuration does not allow other mechanisms of degradation such as lithiation-induced welding of particle clusters or solid electrode interphase (SEI) to be observed [20]. There is a need to develop a closed-cell assembly to observe the electrochemical behavior of electroactive materials in a more realistic battery environment.

With induced plasma, it is difficult to produce particles smaller than about $85 \mathrm{~nm}$ with solid silicon as a precursor. The use of a gaseous precursor such as silane $\left(\mathrm{SiH}_{4}\right)$ may be feasible and lead to the production of amorphous silicon (a-Si) [21] with improved properties. Another interesting alternative process is to produce $10-20 \mathrm{~nm}$ silicon particles by ball milling [22]. However, these large scale production methods require further R\&D.

\section{Acknowledgements}

A special thanks to Maher Boulos and Richard Dolbec at Tekna Plasma Systems inc. for actively working with us to develop of the spherical silicon nanopowder. The in situ high-resolution transmission electron microscopy study described in this paper is supported by the Laboratory Directed Research and Development Program as part of the Chemical Imaging Initiative at Pacific Northwest National Laboratory (PNNL). The work was conducted in the William R. Wiley Environmental Molecular Sciences Laboratory (EMSL), a national scientific user facility sponsored by DOE's Office of Biological and Environmental Research at PNNL. PNNL is operated by Battelle for the Department of Energy under Contract DE-AC05-76RLO1830. We would like also to acknowledge DOE- BATT program (Lawrence Berkeley National Laboratory) and Hydro-Québec for financial support. 


\section{References}

[1] M.N. Obrovac, L. Christensen, D.B. Le, J.R. Dahn, Alloy Design for Lithium-Ion Battery Anodes, Journal of The Electrochemical Society, 154 (2007) A849-A855.

[2] H.S. Kim, K.Y. Chung, B.W. Cho, Electrochemical properties of carbon-coated Si/B composite anode for lithium ion batteries, Journal of Power Sources, 189 (2009) 108-113.

[3] J.H. Ryu, J.W. Kim, Y.-E. Sung, S.M. Oh, Failure Modes of Silicon Powder Negative Electrode in Lithium Secondary Batteries, Electrochemical and Solid-State Letters, 7 (2004) A306-A309.

[4] M. Yoshio, S. Kugino, N. Dimov, Electrochemical behaviors of silicon based anode material, Journal of Power Sources, 153 (2006) 375-379.

[5] J. Graetz, C.C. Ahn, R. Yazami, B. Fultz, Highly Reversible Lithium Storage in Nanostructured Silicon, Electrochemical and Solid-State Letters, 6 (2003) A194-A197.

[6] X.-W. Zhang, P.K. Patil, C. Wang, A.J. Appleby, F.E. Little, D.L. Cocke, Electrochemical performance of lithium ion battery, nano-silicon-based, disordered carbon composite anodes with different microstructures, Journal of Power Sources, 125 (2004) 206-213.

[7] J.P. Maranchi, A.F. Hepp, P.N. Kumta, High Capacity, Reversible Silicon Thin-Film Anodes for Lithium-Ion Batteries, Electrochemical and Solid-State Letters, 6 (2003) A198-A201.

[8] K.-L. Lee, J.-Y. Jung, S.-W. Lee, H.-S. Moon, J.-W. Park, Electrochemical characteristics of a-Si thin film anode for Li-ion rechargeable batteries, Journal of Power Sources, 129 (2004) 270274.

[9] P.R. Abel, Y.-M. Lin, H. Celio, A. Heller, C.B. Mullins, Improving the Stability of Nanostructured Silicon Thin Film Lithium-Ion Battery Anodes through Their Controlled Oxidation, ACS Nano, 6 (2012) 2506-2516. 
[10] M.T. McDowell, S.W. Lee, J.T. Harris, B.A. Korgel, C. Wang, W.D. Nix, Y. Cui, In Situ TEM of Two-Phase Lithiation of Amorphous Silicon Nanospheres, Nano Letters, 13 (2013) 758764.

[11] J.M. Yuk, H.K. Seo, J.W. Choi, J.Y. Lee, Anisotropic Lithiation Onset in Silicon Nanoparticle Anode Revealed by in Situ Graphene Liquid Cell Electron Microscopy, ACS Nano, 8 (2014) 7478-7485.

[12] M. Gu, L.R. Parent, B.L. Mehdi, R.R. Unocic, M.T. McDowell, R.L. Sacci, W. Xu, J.G. Connell, P. Xu, P. Abellan, X. Chen, Y. Zhang, D.E. Perea, J.E. Evans, L.J. Lauhon, J.-G. Zhang, J. Liu, N.D. Browning, Y. Cui, I. Arslan, C.-M. Wang, Demonstration of an Electrochemical Liquid Cell for Operando Transmission Electron Microscopy Observation of the Lithiation/Delithiation Behavior of Si Nanowire Battery Anodes, Nano Letters, 13 (2013) 61066112.

[13] M. Boulos, Plasma power can make better powders, Metal Powder Report, 59 (2004) 16-21.

[14] G. Jiayin, F. Xiaobao, R. Dolbec, X. Siwen, J. Jurewicz, M. Boulos, Development of Nanopowder Synthesis Using Induction Plasma, Plasma Science and Technology, 12 (2010) 188. [15] R.A. Huggins, Advanced Batteries: Materials Science Aspects, Springer London, Limited, 2009.

[16] G. Liu, S. Xun, N. Vukmirovic, X. Song, P. Olalde-Velasco, H. Zheng, V.S. Battaglia, L. Wang, W. Yang, Polymers with Tailored Electronic Structure for High Capacity Lithium Battery Electrodes, Advanced Materials, 23 (2011) 4679-4683.

[17] S.W. Song, S.W. Baek, Silane-derived SEI stabilization on thin-film electrodes of nanocrystalline Si for Lithium batteries, Electrochemical and Solid-State Letters, 12 (2009) A23A27. 
[18] X.H. Liu, L. Zhong, S. Huang, S.X. Mao, T. Zhu, J.Y. Huang, Size-Dependent Fracture of Silicon Nanoparticles During Lithiation, ACS Nano, 6 (2012) 1522-1531.

[19] X.H. Liu, H. Zheng, L. Zhong, S. Huang, K. Karki, L.Q. Zhang, Y. Liu, A. Kushima, W.T. Liang, J.W. Wang, J.-H. Cho, E. Epstein, S.A. Dayeh, S.T. Picraux, T. Zhu, J. Li, J.P. Sullivan,

J. Cumings, C. Wang, S.X. Mao, Z.Z. Ye, S. Zhang, J.Y. Huang, Anisotropic Swelling and Fracture of Silicon Nanowires during Lithiation, Nano Letters, 11 (2011) 3312-3318.

[20] H. Wu, Y. Cui, Designing nanostructured Si anodes for high energy lithium ion batteries, Nano Today, 7 (2012) 414-429.

[21] W.O. Filtvedt, H. Klette, A. Holt, Production of Tailored Silicon Nano Particles, Silicon for the Chemical and Solar Industry XII, Trondheim, Norway, 2014, pp. 259-264.

[22] K. Zaghib, A. Guerfi, D. Leblanc, Particulate anode materials and methods for their preparation, US 2014/0246398, 2014.

\section{Figures captions}

Figure 1. Schematic of nanopowder synthesis using induction plasma torch.

Figure 2. Schematic drawing showing the setup of the open-cell configuration.

Figure 3. (a) SEM micrograph, (b) TEM micrograph, (c) XRD diffractogram and (d) Particle size distribution of the silicon nanopowder.

Figure 4. (a) Formation cycles of the $\mathrm{Si} / \mathrm{Li}$ coin cell, (b) Cycle life of the $\mathrm{Si} / \mathrm{Li}$ coin cell.

Figure 5. (a) Before contact, (b) rapid lithiation at contact and (c) end of lithiation. 


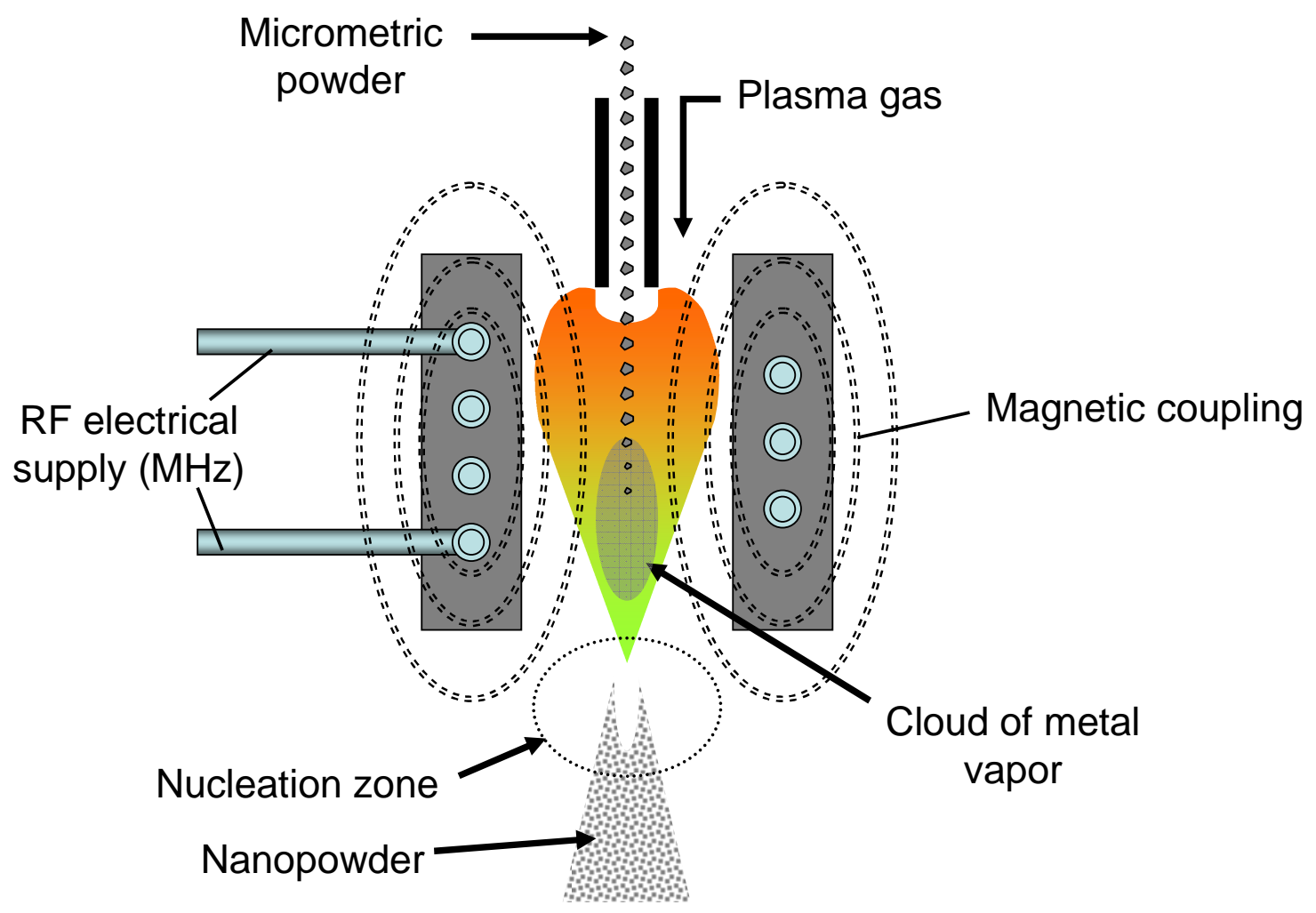

Fig.1 


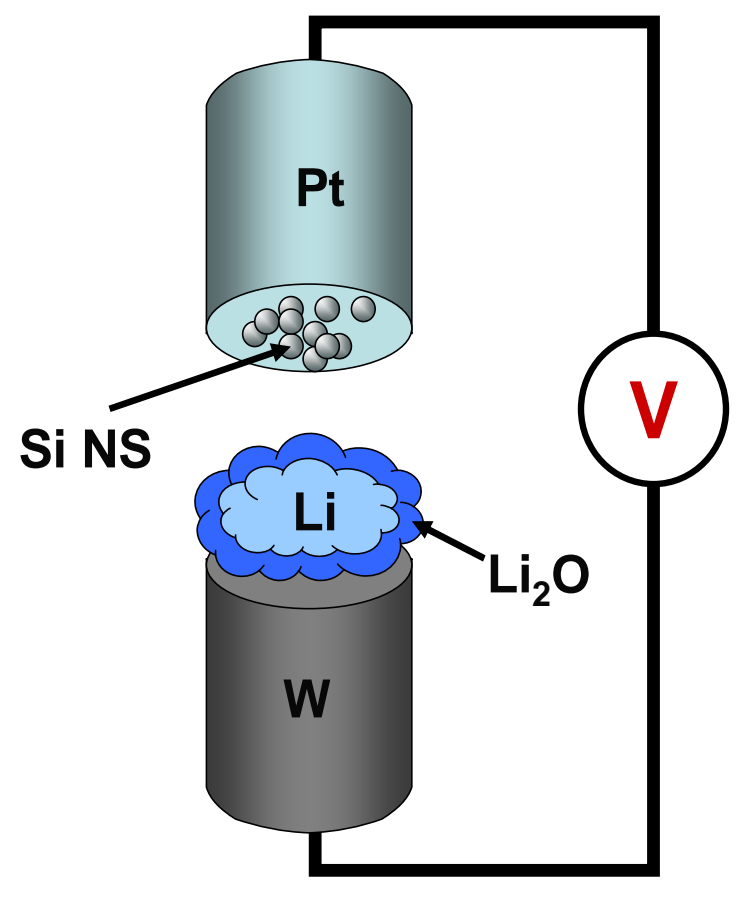

Fig.2 
(a)

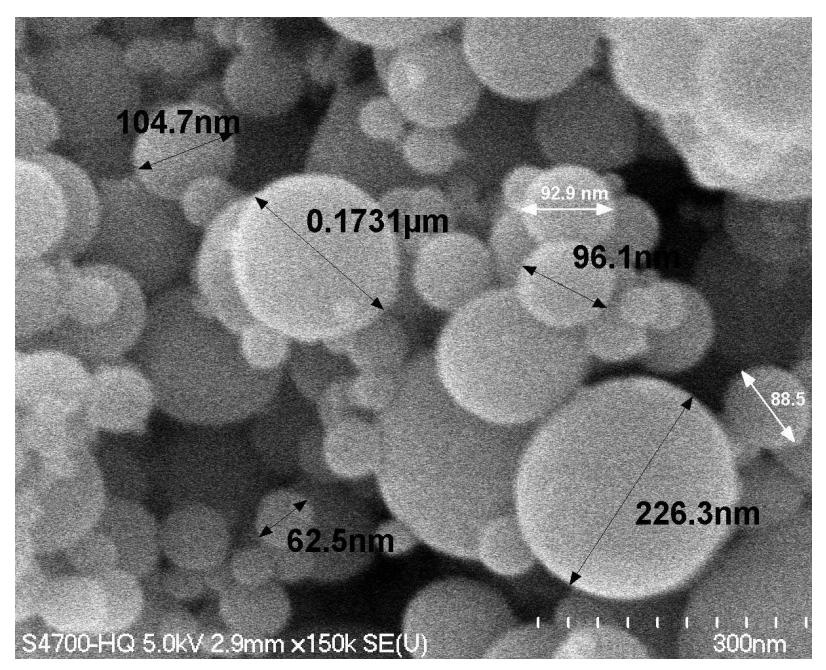

(c)

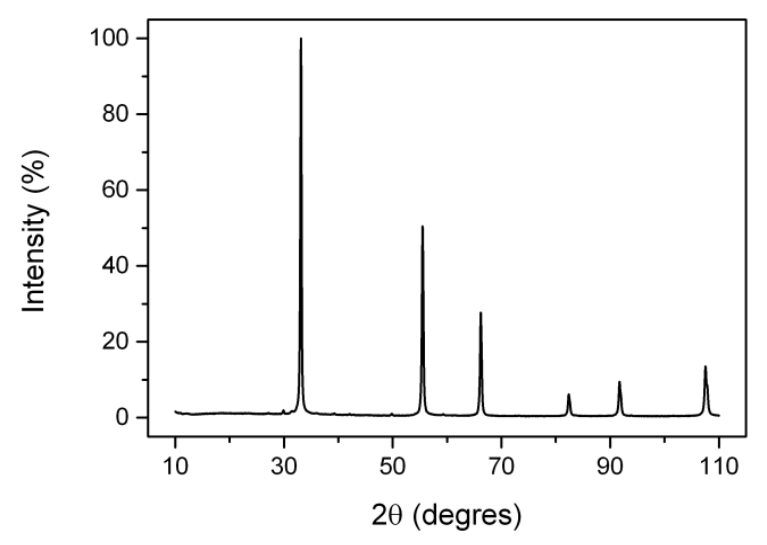

(b)

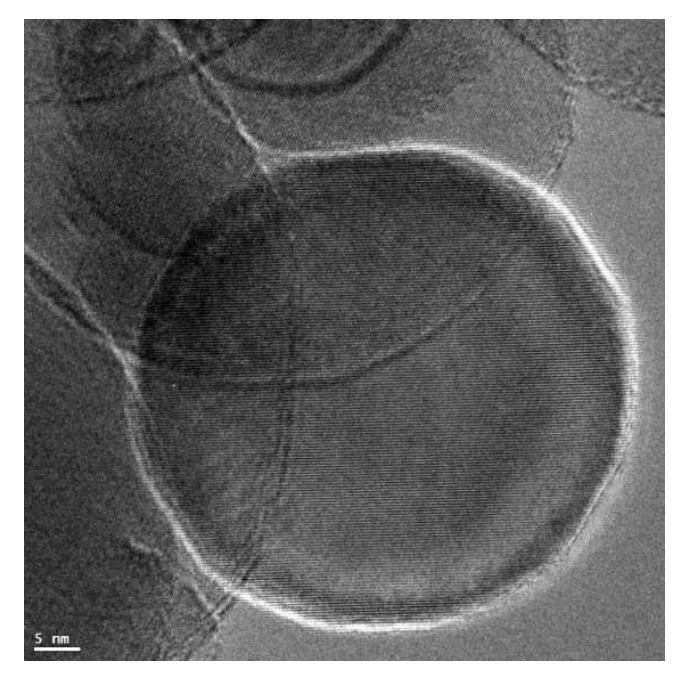

(d)

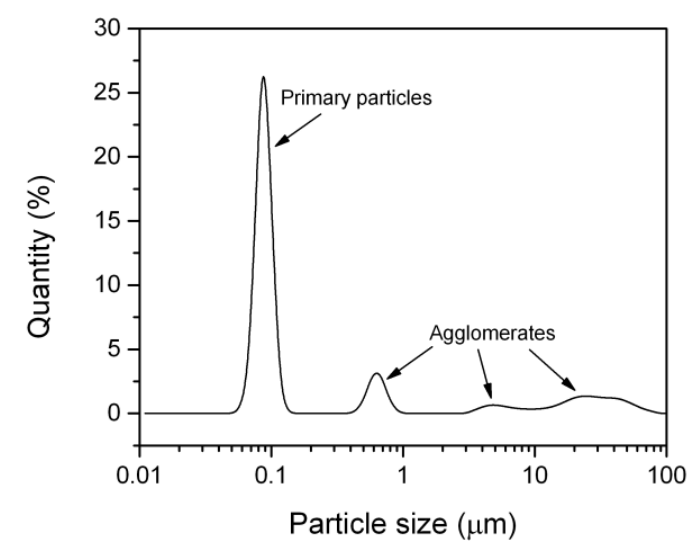

Fig.3 
(a)

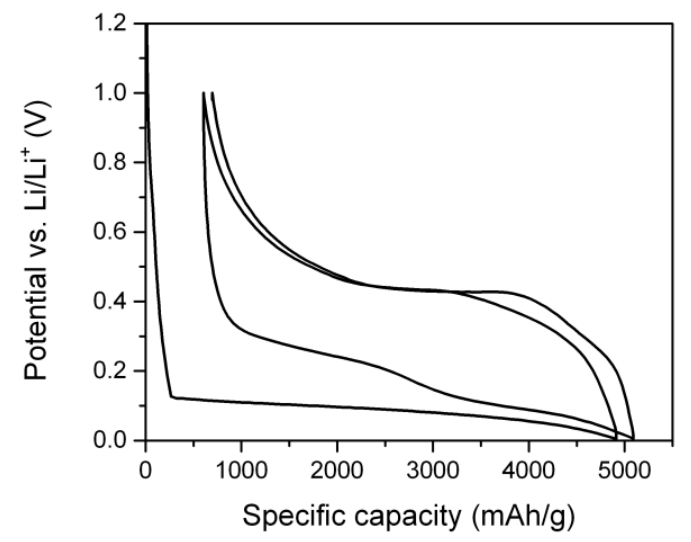

(b)

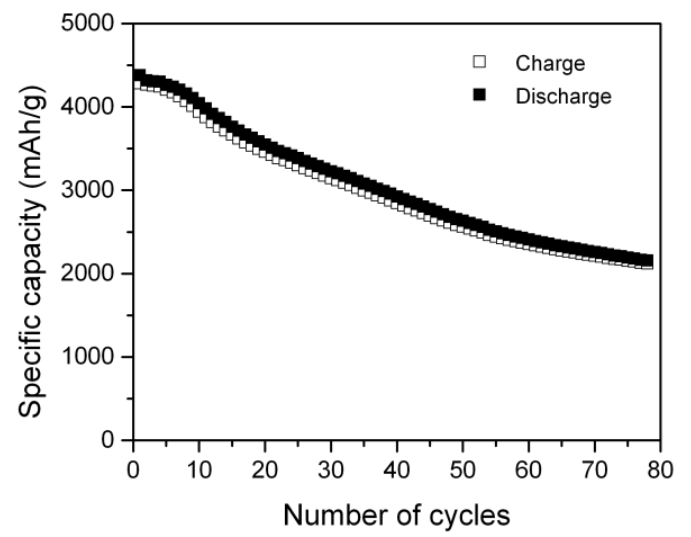

Fig.4 
(a)

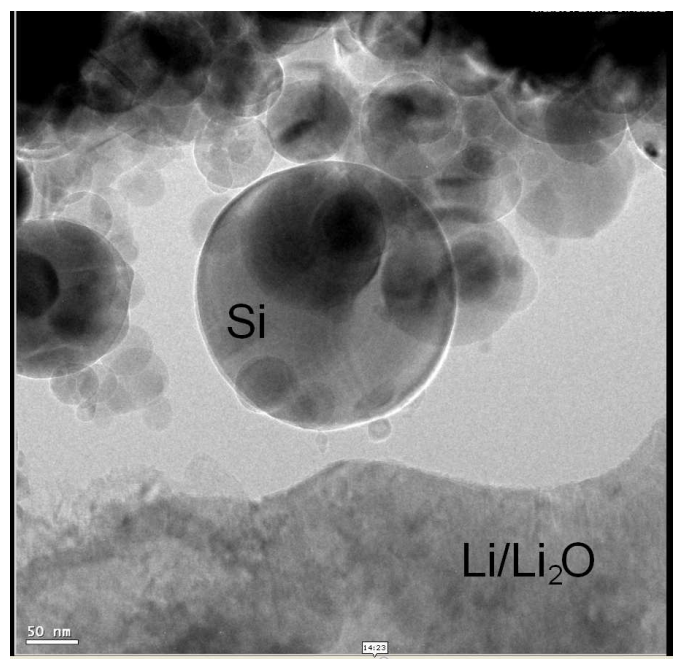

(b)

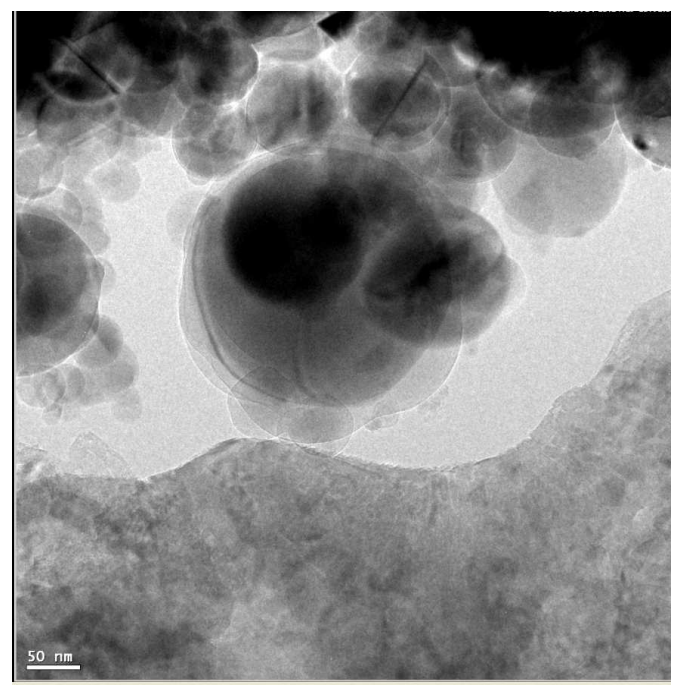

(c)

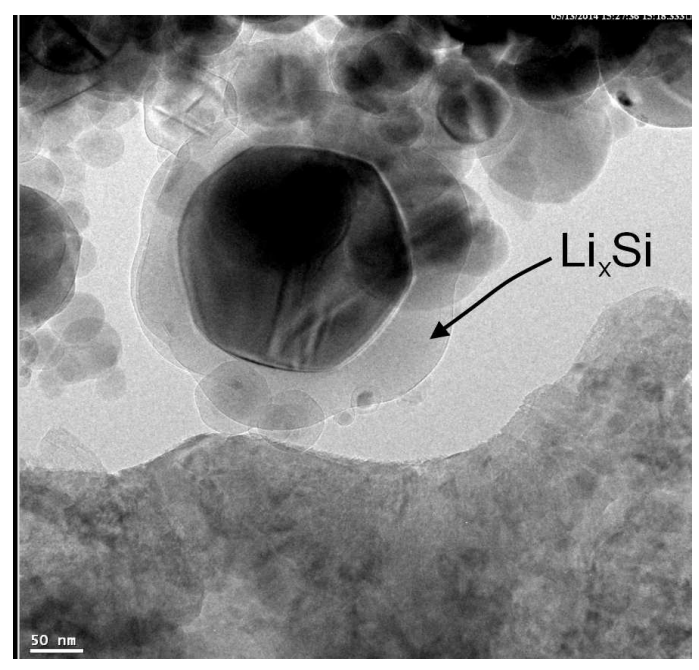

Fig.5 
- Morphological characterisation of crystalline silicon synthesized by induced plasma atomization

- Electrochemical measurements of high gravimetric capacity nano Si (4900 $\mathrm{mAh} / \mathrm{g}$ )

- In situ TEM of single particle volume expansion using open-cell configuration. 